\title{
Moderation of weight misperception on the associations between obesity indices and cardiovascular disease risk
}

Kayoung Lee ( $\sim$ kayoung.fmlky@gmail.com)

Inje University College of Medicine Busan Paik Hospital https://orcid.org/0000-0002-2816-554X

\section{Research Article}

Keywords: weight misperception, cardiovascular disease risk, moderation, obesity indices, gender

Posted Date: December 2nd, 2021

DOI: https://doi.org/10.21203/rs.3.rs-1129261/v1

License: (c) (1) This work is licensed under a Creative Commons Attribution 4.0 International License.

Read Full License 


\section{Abstract}

\section{Purpose}

To evaluate whether weight misperception is associated with estimated cardiovascular disease (CVD) risk and whether gender moderates the association between obesity indices and CVD risk.

\section{Methods}

In 7836 men and 10299 women aged 40-79 years without CVD history from the 2014-2018 Korea National Health and Nutrition Examination Survey, the risk of 10-year atherosclerotic cardiovascular disease (ASCVD) was calculated using Pooled Cohort Equations. Weight misperception was defined as accurate estimation, overestimation, or underestimation by comparing perceived body shape to actual weight category. Obesity indices were BMI and waist circumference (WC).

\section{Results}

In fully-adjusted models, odds of 10-year ASCVD risk of $\geq 7.5 \%$ were lower in men with overestimating weight (odd ratio [95\% confidence interval], $0.85[0.73,0.99]$ after adjusting for $\mathrm{BMl} ; 0.79[0.68,0.92]$ after adjusting for WC), but higher in women with underestimating weight $(1.44[1.27,1.63]$ after adjusting for BMI; $1.42[1.26,1.61]$ after adjusting for WC) compared to those with accurate weight estimates. Compared to women with accurate weight estimates, the ASCVD risk associated with obesity indices was higher in those who underestimated weight ( $\mathrm{B}[95 \% \mathrm{Cl}, 0.33[0.23,0.43]$ for $\mathrm{BMl} ; 0.16[0.13,0.20]$ for WC), whereas it was lower in those who overestimated weight $(-0.15[-0.28,-0.02]$ for $\mathrm{BMI} ;-0.07[-0.11,-0.03]$ for WC). In men, weight misperception did not moderate the association between obesity indices and the ASCVD risk.

Conclusion

Weight misperception was associated with CVD risk independently across gender and moderates the association between obesity indices and CVD risk in women.

\section{What Is Already Known On This Subject?}

Weight misperception can harm physical and mental health, and it can lead to behaviors like dieting. There is a study looking into the link between weight misperception and CVD risk factors among obese firefighters. However, whether weight misperception moderates the link between obesity indices and CVD risk is unknown.

\section{What This Study Adds?}

This study found that weight misperception is linked with CVD risk independently across gender and that weight misperception moderates the association between obesity indices and CVD risk in women. 


\section{Introduction}

Cardiovascular disease (CVD) is the leading cause of death of non-communicable diseases, and ischemic heart disease and stroke accounted for about 85\% of CVD deaths worldwide in 2017[1] and has ranked second to fourth causes of death in Korea as well [2]. A CVD risk estimation model which predicts the risk of developing CVD [3] can help identify the characteristics of a group or individual at high risk of future CVD. The evidence for the association between indices of obesity such as body mass index (BMI) and waist circumference and CVD morbidity and estimated CVD risk is well established [4-8]. In addition, a study suggests that perception of weight status is associated with an estimated CVD risk [9]. Considering this finding, how one perceives one's weight may be significant in one's risk of CVD.

On the other hand, it can be hypothesized that less accurate weight perception may have a different association with CVD risk than accurate weight perception. Individuals who underestimate their weight may have a higher risk of CVD than those who accurately estimate their weight by neglecting CVD-related health behaviors, including weight management. Conversely, individuals who overestimate their weight are more likely to have a lower risk of CVD by controlling their weight [10]. In addition, considering the gender difference in weight misperception, defined as the difference between actual weight and perceived weight, and health-related behaviors [11, 12], it can be assumed that the association between weight misperception and CVD risk may differ by gender. However, it is not evident whether a less accurate perception of one's weight status is associated with CVD risk independently of obesity indices. Although there is a study for the association between weight misperception and CVD risk factors in firefighters with obesity [13], it is also unclear whether weight misperception moderates the association between obesity indices and CVD risk.

Therefore, this study aimed to evaluate whether weight misperception is associated with estimated CVD risk and moderates the association between obesity indices and CVD risk according to gender using the Korea National Health and Nutrition Examination Survey (KNHNES) data.

\section{Methods}

\section{Study population}

This study was performed using data obtained from the KNHANES 2014-2018 [14]. The survey is a nationwide cross-sectional health survey conducted for non-institutionalized South Koreans; it employs a rolling sampling design that involves a complex, stratified, and multistage probability cluster survey [15]. Of 31,310 adults aged 19 to 80 years, the present study included participants between 40 and 79 years who were free from CVD and had all study variables, including components of the 10-year ASCVD risk calculation, body shape perception, anthropometric data, and the covariates. The final dataset comprised data for 18,135 participants (7,836 men and 10,299 women). Written informed consent was obtained from all the participants. The current study and the original KNHANES 2014-2017 were classified under 
the exemption category for ethical review in the Bioethics and Safety Act. The ethical review board of the Korea Centers for Disease Control approved the KNHANES 2018 (approval number: 2018-01-03-P-A) [14].

\section{Anthropometric measurements}

BMI was calculated as the measured weight in kilograms divided by height in meters squared. BMI was categorized into $<18.5 \mathrm{~kg} / \mathrm{m}^{2}$ (underweight), $18.5-24.9 \mathrm{~kg} / \mathrm{m}^{2}$ (normal weight), $25.0-29.9 \mathrm{~kg} / \mathrm{m}^{2}$ (overweight), and $\geq 30.0 \mathrm{~kg} / \mathrm{m}^{2}$ (obesity) [11]. Waist circumference was measured to the nearest $0.1 \mathrm{~cm}$ at the end of normal expiration at the midpoint between the lowest rib and the iliac crest.

\section{Perception and misperception of weight status}

Five categories of self-perceived weight status were determined in self-administered questionnaires.

The questions was, "How do you perceive your current body shape?" This question had five possible answers, namely, "very thin," "somewhat thin," "just right," "somewhat fat," and "very fat." [14] The thin (very and somewhat) responses were combined into one level to match the BMI categories [11]. Weight misperception was determined as accurate estimation, overestimation, or underestimation by comparing perceived body shape with actual weight category. Overestimation was defined as when the perceived body shape was greater than the actual weight category, and underestimation was defined when the perceived body shape was less than the actual weight category.

\section{Estimated cardiovascular disease risk}

The gender-specific Pooled Cohort Equations for non-Hispanic whites were used to calculate the 10-year risk of a first hard atherosclerotic cardiovascular disease (ASCVD) event. The variables necessary for Pooled Cohort Equations were age, gender, total cholesterol, high-density lipoprotein cholesterol, systolic blood pressure, antihypertensive therapy, diabetes, and current smoking [16]. The measurements and survey were performed after the participants fasted for at least 8 hours. Blood pressure was measured thrice using a sphygmomanometer (Baumanometer ${ }^{\circledR}$ Wall Unit 33 [0850], Baum, U.S.) according to the standard protocol [17]; the average of second and third measures constituted the examination blood pressure. Serum glucose levels (using the hexokinase ultraviolet method) and hemoglobin A1C (using the high-performance liquid chromatography method) were assessed. Diabetes mellitus was defined if any one of serum fasting glucose levels $\geq 7.0 \mathrm{mmol} / \mathrm{L}(126 \mathrm{mg} / \mathrm{dL})$, hemoglobin $\mathrm{A} 1 \mathrm{C} \geq 6.5 \%$ [18], or selfreported history of diabetes mellitus was satisfied. Total cholesterol and high-density lipoprotein cholesterol levels were determined using a standard enzymatic method. Cigarette smoking status was ascertained by self-report. The research assistants confirmed antihypertensive medication use. The Pooled Cohort Equations for non-Hispanic whites had good discrimination for CVD prediction in Korean men and women [19].

\section{Covariates}

Self-reported questionnaires and interviews were used to investigate sociodemographic factors (age, sex, income level, and educational attainment), health-related behaviors (alcohol use, physical activity, and 
strength exercises), concurrent diseases, and depressive mood. The covariates were categorized as follows: income level (low to middle-low vs. middle-high to high), educational attainment ( $\leq$ graduated high school vs. > graduated high school), alcohol consumption (yes vs. no for drinking $\geq$ once per month in the past year), physical endurance activity (yes vs. no for engaging in high-intensity activity for $>75$ $\mathrm{min}$ /week, moderate-intensity activity for $>150 \mathrm{~min} /$ week, or a combination of both), strength exercises (yes vs. no for $\geq$ once/week), concurrent diseases (yes vs. no for dyslipidemia, pulmonary tuberculosis, asthma, arthritis, depression, liver cirrhosis, kidney failure, and cancers), and depressive mood for more than two weeks in a row (yes vs. no).

\section{Statistical Analyses}

All analyses were weighted to account for the multistage, clustered probability sampling for KNHANES. Chi-square test of complex sampling design or general linear model of complex sampling design was used to compare the 10-year ASCVD risk, BMI category, perceived body shape, and covariates according to the weight misperception. The general linear model of complex sampling design was performed for the association between weight misperception and the 10-year ASCVD risk after adjusting for age and other covariates (Model 1); the covariates of model 1 and BMI (Model 2); and the covariates of model 1 and waist circumference (Model 3). As there was a significant interaction between gender and weight misperception $(P<0.001)$ in those models, these analyses were conducted in each gender. A logistic regression model of complex sampling design was conducted for the association between weight misperception and 10-year ASCVD risk of $\geq 7.5 \%$ using the same models applied in general linear models.

Gender-specific analysis of statistical moderation of weight misperception in the association between BMI (or waist circumference) and the 10-year ASCVD risk was conducted using the PROCESS macro of SPSS version 26.0 (PROCESS V3.5), developed by Hayes [20,21] after adjusting for all covariates. Moderation means that the association between BMI (or waist circumference) and the 10-year ASCVD risk varies with weight misperception. A test of linear moderation is conducted with a hypothesis test or confidence interval for the regression coefficient for the interaction between BMI (or waist circumference) and weight misperception, which is equivalent to an inference about whether the weight for the weight misperception in the linear function defining the effect of $\mathrm{BMI}$ is equal to zero. If the weight for interaction is different from zero, the effect of BMI (or waist circumference) on the ASCVD risk varies with weight misperception. All analyses were performed using the IBM Statistical Package for the Social Sciences, software version 27 (IBM Corp., Armonk, NY, USA).

\section{Results}

In representative Korean participants aged 40-79 years without a history of CVD, weight estimation was accurate in $60.8 \%$, while weight was overestimated in $19.2 \%$ and underestimated in $20.0 \%$. Participants who underestimated their weight had a higher 10-year ASCVD risk than those who accurately estimated or overestimated their weight. Those who underestimated their weight were more likely to be older, more men, have lower educational and economic levels, be current smokers, drinkers, and less physically 
active, have more comorbidities, and have depressive moods than those who accurately estimated or overestimated their weight. Among those who underestimated their weight, $7.2 \%$ perceived their weight as somewhat fat, although $39 \%$ had a BMI $\geq 25 \mathrm{~kg} / \mathrm{m}^{2}$ (Table 1). 
Table 1

Comparison of characteristics according to weight estimation in Korean adults aged 40-79 years without a CVD history

\begin{tabular}{|c|c|c|c|c|c|c|}
\hline & \multirow{2}{*}{$\begin{array}{l}\text { All } \\
(n=18,135)\end{array}$} & \multicolumn{3}{|c|}{ Weight misperception } & \multirow{2}{*}{$\begin{array}{l}\mathrm{Chi}^{2} / \\
\text { Wald F }\end{array}$} & \multirow[t]{2}{*}{$\mathrm{P}^{*}$} \\
\hline & & $\begin{array}{l}\text { Under- } \\
\text { estimation } \\
(20.0 \pm 0.2 \%)\end{array}$ & $\begin{array}{l}\text { Accurate } \\
\text { estimation } \\
(60.8 \pm 0.2 \%)\end{array}$ & $\begin{array}{l}\text { Over- } \\
\text { estimation } \\
(19.2 \pm 0.2 \%)\end{array}$ & & \\
\hline $\begin{array}{l}\text { 10-y ASCVD risk } \\
(\%)\end{array}$ & $8.7 \pm 0.1$ & $12.4 \pm 0.1$ & $8.5 \pm 0.1^{\dagger}$ & $5.7 \pm 0.1^{\dagger}$ & 840.7 & $<0.001$ \\
\hline Age (y) & $55.8 \pm 0.1$ & $59.0 \pm 0.1$ & $55.5 \pm 0.1^{\dagger}$ & $53.4 \pm 0.1^{\dagger}$ & 584.2 & $<0.001$ \\
\hline Women & $52.2 \pm 0.2$ & $36.8 \pm 0.5$ & $50.8 \pm 0.3$ & $72.6 \pm 0.5$ & 777.8 & $<0.001$ \\
\hline $\begin{array}{l}\geq \text { Graduated high } \\
\text { school }\end{array}$ & $67.1 \pm 0.3$ & $57.3 \pm 0.6$ & $68.7 \pm 0.3$ & $72.3 \pm 0.3$ & 178.9 & $<0.001$ \\
\hline $\begin{array}{l}\text { Income } \geq 3 r d \\
\text { quartile }\end{array}$ & $52.2 \pm 0.3$ & $47.9 \pm 0.5$ & $53.4 \pm 0.4$ & $53.0 \pm 0.5$ & 28.9 & $<0.001$ \\
\hline Current smoker & $18.7 \pm 0.2$ & $25.8 \pm 0.5$ & $18.3 \pm 0.3$ & $12.4 \pm 0.4$ & 176.5 & $<0.001$ \\
\hline $\begin{array}{l}\text { Alcohol drink } \geq \\
\text { once/m }\end{array}$ & $54.1 \pm 0.2$ & $54.9 \pm 0.5$ & $55.5 \pm 0.3$ & $49.1 \pm 0.5$ & 37.1 & $<0.001$ \\
\hline $\begin{array}{l}\text { Regular physical } \\
\text { activity }\end{array}$ & $45.4 \pm 0.2$ & $40.8 \pm 0.5$ & $46.6 \pm 0.3$ & $46.6 \pm 0.5$ & 32.6 & $<0.001$ \\
\hline $\begin{array}{l}\text { Resistance } \\
\text { exercise } \geq \text { once/w }\end{array}$ & $24.0 \pm 0.2$ & $24.7 \pm 0.5$ & $25.2 \pm 0.2$ & $19.1 \pm 0.4$ & 46.4 & $<0.001$ \\
\hline $\begin{array}{l}\text { BMI categories } \\
\left(\mathrm{kg} / \mathrm{m}^{2}\right)\end{array}$ & & & & & 1020.6 & $<0.001$ \\
\hline$<18.5$ & $2.4 \pm 0.1$ & & $3.5 \pm 0.1$ & $1.6 \pm 0.1$ & & \\
\hline $18.5 \sim<25.0$ & $61.9 \pm 0.2$ & $61.1 \pm 0.5$ & $58.0 \pm 0.3$ & $74.9 \pm 0.4$ & & \\
\hline $25.0 \sim 29.9$ & $31.4 \pm 0.2$ & $30.9 \pm 0.5$ & $34.1 \pm 0.3$ & $23.5 \pm 0.4$ & & \\
\hline$\geq 30$ & $4.3 \pm 0.1$ & $8.1 \pm 0.3$ & $4.4 \pm 0.1$ & & & \\
\hline $\begin{array}{l}\text { Perceived body } \\
\text { shape }\end{array}$ & & & & & 1029.8 & $<0.001$ \\
\hline Thin & $14.7 \pm 0.1$ & $63.0 \pm 0.5$ & $3.5 \pm 0.1$ & & & \\
\hline Just right & $41.5 \pm 0.2$ & $29.8 \pm 0.4$ & $58.0 \pm 0.3$ & $1.5 \pm 0.1$ & & \\
\hline Somewhat fat & $35.9 \pm 0.2$ & $7.2 \pm 0.3$ & $34.1 \pm 0.3$ & $71.6 \pm 0.5$ & & \\
\hline Very fat & $7.8 \pm 0.1$ & & $4.4 \pm 0.1$ & $26.9 \pm 0.5$ & & \\
\hline
\end{tabular}




\begin{tabular}{|c|c|c|c|c|c|c|}
\hline & \multirow{2}{*}{$\begin{array}{l}\text { All } \\
(n=18,135)\end{array}$} & \multicolumn{3}{|c|}{ Weight misperception } & \multirow{2}{*}{$\begin{array}{l}\mathrm{Chi}^{2} / \\
\text { Wald F }\end{array}$} & \multirow[t]{2}{*}{$\mathbf{P}^{*}$} \\
\hline & & $\begin{array}{l}\text { Under- } \\
\text { estimation } \\
(20.0 \pm 0.2 \%)\end{array}$ & $\begin{array}{l}\text { Accurate } \\
\text { estimation } \\
(60.8 \pm 0.2 \%)\end{array}$ & $\begin{array}{l}\text { Over- } \\
\text { estimation } \\
(19.2 \pm 0.2 \%)\end{array}$ & & \\
\hline $\begin{array}{l}\text { Concurrent } \\
\text { diseases }\end{array}$ & $35.0 \pm 0.2$ & $36.5 \pm 0.5$ & $34.3 \pm 0.3$ & $35.8 \pm 0.5$ & 5.9 & $<0.001$ \\
\hline Depressive mood & $4.6 \pm 0.0$ & $5.5 \pm 0.1$ & $4.1 \pm 0.0$ & $5.1 \pm 0.1$ & 11.7 & $<0.001$ \\
\hline \multicolumn{7}{|c|}{$\begin{array}{l}\text { ASCVD, atherosclerotic cardiovascular disease; CVD, cardiovascular disease; m, month; w, week; BMI, } \\
\text { body mass index. }\end{array}$} \\
\hline \multicolumn{7}{|c|}{ Values represent weighted $\% \pm$ standard error or estimated marginal mean \pm standard error. } \\
\hline
\end{tabular}

In men, the 10-year ASCVD risk was lower in those who overestimated their weight than those with accurate weight estimates after adjusting for the covariates and waist circumference (Model 3). In contrast, it was not significantly different by weight misperception groups after adjusting for the covariates and BMI. Compared to those with accurate weight estimates, odds of 10-year ASCVD risk of $\geq$ $7.5 \%$ were $15 \%-21 \%$ lower in those with overestimating weight in fully adjusted models (Model 2 and Model 3).

In women, the 10-year ASCVD risk was higher in those who underestimated their weight than those with accurate weight estimates after adjusting for age, other covariates, and BMI (Model 2). In the model adjusted for waist circumference (Model 3), the 10-year ASCVD risk was higher in those who underestimated their weight and was lower in those who overestimated their weight than those with accurate weight estimates. Compared to those with accurate weight estimates, odds of 10-year ASCVD risk of $\geq 7.5 \%$ were $42 \%-44 \%$ higher in those with underestimating weight in fully adjusted models (Model 2 and Model 3, Table 2). 
Table 2

Gender-specific association between weight misperception and 10-year ASCVD risk in Korean adults aged 40-79 years without a CVD history

Model 1

Model 2

Model 3

Men

Weight misperception

10-year ASCVD risk (\%)

Under

$11.5 \pm 0.1^{\dagger}$

$11.8 \pm 0.1$

$11.9 \pm 0.1$

Accurate

$11.8 \pm 0.1$

$11.7 \pm 0.1$

$11.7 \pm 0.1$

Over

$11.6 \pm 0.1^{\dagger}$

$11.4 \pm 0.1$

$11.2 \pm 0.2^{\dagger}$

Weight misperception

10-year ASCVD risk $\geq 7.5 \%$

Under

$0.82(0.74,0.90)$

$0.96(0.87,1.06)$

$0.99(0.89,1.10)$

Accurate

1.00

1.00

1.00

Over

$0.87(0.75,1.02)$

$0.85(0.73,0.99)$

$0.79(0.68,0.92)$

Women

Weight misperception

Under

Accurate

Over

Weight misperception

Under

Accurate

Over

ASCVD, atherosclerotic cardiovascular disease; CVD, cardiovascular disease; BMI, body mass index.

Values represent estimated marginal mean \pm standard error using complex sample general linear model or odds ratio ( $95 \%$ confidence interval) using complex sample logistic regression after adjusting for age, education, income, alcohol drink, physical activity, resistance exercises, depressive mood, and concurrent diseases (Model 1); the same covariates of model 1 and BMI (Model 2); the same covariates of model 1 and waist circumference (Model 3).

${ }^{\dagger} \mathrm{P}<0.05$ compared with accurate weight estimation using a simple contrast test.

The moderation of weight misperception on the association between obesity indices and the 10-year ASCVD risk was significant in women but not in men. In women, compared to those with accurate weight estimates, the ASCVD risk associated with obesity indices was higher in those who underestimated their 
weight ( $\mathrm{B}[95 \% \mathrm{Cl}], 0.33[0.23,0.43]$ for $\mathrm{BMl} ; 0.16[0.13,0.20]$ for waist circumference), whereas it was lower in those who overestimated their weight $(-0.15[-0.28,-0.02]$ for $\mathrm{BMI} ;-0.07[-0.11,-0.03]$ for waist circumference) (Table 3)

Table 3

Weight misperception as a moderator in the associations between anthropometrics and the 10-year ASCVD risk among Korean adults aged 40-79 years without a CVD history

\begin{tabular}{|c|c|c|}
\hline & Men & Women \\
\hline \multicolumn{3}{|l|}{ Association between BMI and ASCVD risk } \\
\hline BMI & $0.36(0.28,0.43)$ & $0.07(0.02,0.12)$ \\
\hline Weight overestimation (vs. accurate estimation) & $-3.57(-9.27,2.12)$ & $3.47(0.28,6.66)$ \\
\hline Weight underestimation (vs. accurate estimation) & $-1.08(-3.97,1.81)$ & $-5.83(-8.22,-3.44)$ \\
\hline BMl×weight overestimation (vs. accurate estimation) & $0.14(-0.09,0.37)$ & $-0.15(-0.28,-0.02)$ \\
\hline BMl×weight underestimation (vs. accurate estimation) & $0.04(-0.09,0.16)$ & $0.33(0.23,0.43)$ \\
\hline \multicolumn{3}{|l|}{ Association between WC and ASCVD risk } \\
\hline WC & $0.14(0.11,0.17)$ & $0.05(0.03,0.07)$ \\
\hline Weight overestimation (vs. accurate estimation) & $-3.59(-10.40,3.22)$ & $5.68(2.24,9.11)$ \\
\hline Weight underestimation (vs. accurate estimation) & $-3.47(-7.19,0.26)$ & $-11.14(-14.17,-8.11)$ \\
\hline WC $\times$ Weight overestimation (vs. accurate estimation) & $0.34(-0.04,0.11)$ & $-0.07(-0.11,-0.03)$ \\
\hline WC $\times$ Weight underestimation (vs. accurate estimation) & $0.04(-0.01,0,09)$ & $0.16(0.13,0.20)$ \\
\hline \multicolumn{3}{|c|}{$\begin{array}{l}\text { ASCVD, atherosclerotic cardiovascular disease; CVD, cardiovascular disease; BMI, body mass index; } \\
\text { WC, waist circumference. }\end{array}$} \\
\hline \multicolumn{3}{|c|}{$\begin{array}{l}\text { Values are regression coefficients }(95 \% \mathrm{Cl}) \text { on the } 10 \text {-year ASCVD risk after adjusting for age, } \\
\text { education, income, alcohol drink, physical activity, resistance exercises, depressive mood, and } \\
\text { concurrent diseases using the PROCESS procedure. }\end{array}$} \\
\hline
\end{tabular}

As shown in Figure 1, the conditional effects of obesity indices on the 10-year ASCVD according to weight misperception risk differed by gender. In women, the positive association between BMI and the ASCVD risk in those who underestimated their weight was greater than other weight misperception groups (effect [95\% Cl], 0.40 [ 0.32, 0.49] for underestimation group; 0.07 [0.02, 0.12] for accurate estimation group; -0.08 $[-0.20,0.04]$ for overestimation group). Similar findings were observed for the association between waist circumference and the ASCVD risk according to weight misperception groups $(0.21[0.18,0.24]$ for underestimation group; $0.05[0.03,0.07]$ for accurate estimation group; $-0.03[-0.06,0.02]$ for overestimation group). In men, the effects of obesity indices on the ASCVD risk were similar by weight misperception groups. 


\section{Discussion}

In this study using representative survey data of Korean adults aged 40-79 years without a history of CVD, there were gender differences in the association between weight misperception and the 10-year ASCVD risk and the moderation of weight misperception on the association between obesity indices and the 10year ASCVD risk. In women, weight underestimation was consistently associated with a higher 10-year ASCVD risk regardless of adjustment for obesity indices. The positive associations between obesity indices and the 10-year ASCVD risk were greater in those who underestimated their weight than those who accurately estimated or overestimated their weight. In men, weight overestimation was associated with a lower 10-year ASCVD risk, and weight misperception did not affect the associations between obesity indices and 10-year ASCVD risk. These findings suggest that weight underestimation may have a detrimental effect on the associations between obesity indices and the 10-year ASCVD risk in women. In general, studies on weight misperception have been focused on body image, body shape dissatisfaction, and weight-related attitudes [22-24]. This study will be meaningful in terms of showing a different aspect from previous studies on weight misperception.

Weight misperception can affect physical and psychological health and manifest in behavior such as dieting [24]. According to a systematic review of adults over 55 years of age, overweight self-perception was associated with the desire for weight loss and attempt to weight control, independently of actual weight status and gender. Conversely, individuals with overweight who underestimated their weight were less likely to make an effort to control weight than those who accurately estimated their weight [22]. In another systematic review concerning weight status perceptions and weight loss attempts, perceived overweight was consistently associated with attempting to lose weight. However, in some participant groups, perceived overweight was associated with lower levels of physical activity, unhealthy eating habits, disordered eating, and weight gain over time [23].

These findings suggest that even if individuals who perceive their weight status as overweight try to lose weight, this may not lead to healthy and effective weight loss. The mechanism that the perception of overweight is not linked to behaviors to improve it can be explained by the phenomenon that individuals who perceive themselves as overweight may have difficulties initiating or maintaining healthy behaviors as they experience stigma [23]. When these findings are applied to explain the mechanisms of this study, women who underestimate their weight are more likely to be overweight than those who accurately estimate or overestimate their weight. They are likely to experience the stigma of being overweight and then neglect healthy habits to lower the risk of ASCVD, resulting in their ASCVD risk being higher than those who accurately estimate or overestimate their weight. Another plausible mechanism may be that women who underestimate their weight tend to be older. Then, they had more components such as hypertension, diabetes, and dyslipidemia included in the ASCVD risk assessment, even when adjusted for age. On the other hand, the inverse association between weight overestimation and the ASCVD risk in men could be explained by the possibility that men who overestimate their weight may be more concerned with health care than those who accurately estimate or underestimate their weight. In this study, the effect of weight underestimation on the associations between obesity indices and the ASCVD 
risk was more significant in women than in men, suggesting that women who underestimate weight may have other factors that increase the risk of ASCVD. In general, women perceive their body heavier, likely due to the idealization of a thin ideal body. Men tend to undervalue their body size, likely due to the idealization of a muscular and larger body [24]. Due to these gender differences, women may experience greater body dissatisfaction and heavy stigma than men. In addition to the gender difference in the experience of the stigma of being overweight, underlying factors such as health beliefs and environmental factors, which influence both weight underestimation and higher ASCVD risk, may differ by gender.

The findings of this study have implications for public health approaches concerning weight misperception in association with the ASCVD risk. Underestimation of weight status in women may be a risk factor for the 10-year ASCVD risk regardless of obesity indices and may further increase the ASCVD risk related to obesity indices. In men, overestimation of weight status may be a protective factor for the ASCVD risk. In this regard, weight misperception may be related to ASCVD risk across gender and influence the association between obesity indices and ASCVD risk in women.

In conclusion, regardless of BMI or waist circumference, weight underestimation in women was associated with a higher level of 10-year ASCVD risk, while weight overestimation in men was associated with a lower level of the ASCVD risk. Furthermore, in women, weight underestimation was associated with a higher level of the ASCVD risk associated with the obesity indices. More longitudinal studies are required to determine the causal pathway between weight misperception and the ASCVD risk and moderation of weight misperception on the association between obesity indices and the ASCVD risk.

\section{Strength And Limits}

A strength of the present study is that it included representative data for Koreans. Considering most studies were conducted for weight-related attitudes related to weight misperception, this study highlighted the importance of weight misperception concerning ASCVD risk. However, a limitation on causality inference due to a cross-sectional study may be inevitable. Thus, the components of ASCVD risk may affect weight misperception. Although a previous study suggested good discrimination of the Pooled Cohort Equations for non-Hispanic whites for CVD prediction in Korean adults, the accuracy of estimated ASCVD risk may differ by gender.

\section{Declarations}

Funding: This work was funded by the Ministry of Education of the Republic of Korea and the National Research Foundation of Korea (NRF-2020S1A5C2A02092454).

Competing Interests: The author has no relevant financial or non-financial interests to declare.

Author Contributions: The author contributes to study conceptualization, methodology, analysis, writingoriginal draft preparation and editing. 
Data Availability: The data underlying this article are available in Korea National Health and Nutrition Examination Survey at https://knhanes.kdca.go.kr/knhanes/eng/index.do.

\section{Acknowledgments}

This work was funded by the Ministry of Education of the Republic of Korea and the National Research Foundation of Korea (NRF-2020S1A5C2A02092454).

\section{References}

1. GBD 2017 Causes of Death Collaborators (2018) Global, regional, and national age-sex-specific mortality for 282 causes of death in 195 countries and territories, 1980-2017: a systematic analysis for the Global Burden of Disease Study 2017. Lancet 392: 1736-1788.https://doi.org/10.1016/s01406736(18)32203-7

2. Statistics on the cause of death in Koreans in 2020. Statistics Korea, 2021.

3. Farzadfar F (2019) Cardiovascular disease risk prediction models: challenges and perspectives. Lancet Glob Health 7: e1288-e1289.https://doi.org/10.1016/s2214-109x(19)30365-1

4. Khan SS, Ning H, Wilkins JT et al. (2018) Association of Body Mass Index With Lifetime Risk of Cardiovascular Disease and Compression of Morbidity. JAMA Cardiol 3: 280287.https://doi.org/10.1001/jamacardio.2018.0022

5. Dis Ineke v, Kromhout D, Geleijnse JM, Boer JMA, Verschuren WM (2009) Body mass index and waist circumference predict both 10-year nonfatal and fatal cardiovascular disease risk: study conducted in 20 000 Dutch men and women aged 20-65 years. Eur J Cardiovasc Prev Rehabil 16: 729734.https://doi.org/10.1097/HJR.0b013e328331dfc0

6. Mongraw-Chaffin ML, Peters SA, Huxley RR, Woodward M (2015) The sex-specific association between $\mathrm{BMI}$ and coronary heart disease: a systematic review and meta-analysis of 95 cohorts with $1 \cdot 2$ million participants. The lancet Diabetes \& endocrinology 3: 437-449.

7. Hu FB, Wang B, Chen C et al. (2000) Body Mass Index and Cardiovascular Risk Factors in a Rural Chinese Population. Am J Epidemiol 151: 88-97.https://doi.org/10.1093/oxfordjournals.aje.a010127

8. Commodore-Mensah Y, Agyemang C, Aboagye JA et al. (2020) Obesity and cardiovascular disease risk among Africans residing in Europe and Africa: the RODAM study. Obes Res Clin Pract 14: 151157.https://doi.org/10.1016/j.orcp.2020.01.007

9. Cullin JM, White KE (2020) Weight perception among US adults predicts cardiovascular risk when controlling for body fat percentage. Am J Hum Biol 32: e23384.https://doi.org/10.1002/ajhb.23384 
10. Yaemsiri S, Slining MM, Agarwal SK (2011) Perceived weight status, overweight diagnosis, and weight control among US adults: the NHANES 2003-2008 Study. Int J Obes (Lond) 35: 1063-

1070.https://doi.org/10.1038/ijo.2010.229

11. Park S, Lee S, Hwang J, Kwon JW (2017) The impact of weight misperception on health-related quality of life in Korean adults (KNHANES 2007-2014): a community-based cross-sectional study. BMJ open 7: e016098-012017-016098.https://doi.org/10.1136/bmjopen-2017-016098 [doi]

12. Duncan DT, Wolin KY, Scharoun-Lee M, Ding EL, Warner ET, Bennett GG (2011) Does perception equal reality? Weight misperception in relation to weight-related attitudes and behaviors among overweight and obese US adults. International Journal of Behavioral Nutrition and Physical Activity 8: 1-9.

13. Baur DM, Christophi CA, Tsismenakis AJ, Jahnke SA, Kales SN (2012) Weight- perception in male career firefighters and its association with cardiovascular risk factors. BMC Public Health 12: 480.https://doi.org/10.1186/1471-2458-12-480

14. Korea Centers for Disease C, Prevention: The Seventh (2016-2018) Korea National Health and Nutrition Examination Survey (KNHANES VII). Guidelines for using raw data. . 2020.

15. Kweon S, Kim Y, Jang MJ et al. (2014) Data resource profile: the Korea National Health and Nutrition Examination Survey (KNHANES). Int J Epidemiol 43: 69-77.https://doi.org/10.1093/ije/dyt228 [doi]

16. Goff DC, Jr., Lloyd-Jones DM, Bennett G et al. (2014) 2013 ACC/AHA guideline on the assessment of cardiovascular risk: a report of the American College of Cardiology/American Heart Association Task Force on Practice Guidelines. Circulation 129: S49-

73.https://doi.org/10.1161/01.cir.0000437741.48606.98

17. Korea Centers for Disease Control P: Procedural manual of The Sixth (2013-2015) Korea National Health and Nutrition Examination Survey. Oson, South Korea, Korea Centers for Disease Control Prevention, 2013.

18. (2013) American Diabetes Association. Diagnosis and classification of diabetes mellitus. Diabetes Care 36: S67-S74.https://doi.org/10.2337/dc13-S067

19. Bae JH, Moon MK, Oh S, Koo BK, Cho NH, Lee MK (2020) Validation of risk prediction models for atherosclerotic cardiovascular disease in a prospective Korean community-based cohort. Diabetes Metab J 44: 458-469.https://doi.org/10.4093/dmj.2019.0061

20. Hayes AF, Rockwood NJ (2017) Regression-based statistical mediation and moderation analysis in clinical research: Observations, recommendations, and implementation. Behav Res Ther 98: 3957.https://doi.org/S0005-7967(16)30188-7 [pii]

21. Hayes AF: Introduction to mediation, moderation, and conditional process analysis: a regressionbased approach, New York: The Guilford Press, 2013. 
22. Bouzas C, Bibiloni MDM, Tur JA (2019) Relationship between Body Image and Body Weight Control in Overweight $\geq 55$-Year-Old Adults: A Systematic Review. Int J Environ Res Public Health 16:https://doi.org/10.3390/ijerph16091622

23. Haynes A, Kersbergen I, Sutin A, Daly M, Robinson E (2018) A systematic review of the relationship between weight status perceptions and weight loss attempts, strategies, behaviours and outcomes. Obes Rev 19: 347-363.https://doi.org/10.1111/obr.12634

24. Hosseini SA, Padhy RK: Body Image Distortion. StatPearls. Treasure Island (FL), StatPearls Publishing Copyright @ 2021, StatPearls Publishing LLC., 2021.

\section{Tables}


Table 1. Comparison of characteristics according to weight estimation in Korean adults aged 40-79 years without a CVD history

\begin{tabular}{|c|c|c|c|c|c|c|}
\hline & \multirow{2}{*}{$\begin{array}{l}\text { All } \\
(n=18,135)\end{array}$} & \multicolumn{3}{|c|}{ Weight misperception } & \multirow{2}{*}{$\begin{array}{l}\mathrm{Chi}^{2} / \\
\text { Wald F }\end{array}$} & \multirow[t]{2}{*}{$P^{*}$} \\
\hline & & $\begin{array}{l}\text { Under- } \\
\text { estimation } \\
(20.0 \pm 0.2 \%)\end{array}$ & $\begin{array}{l}\text { Accurate } \\
\text { estimation } \\
(60.8 \pm 0.2 \%)\end{array}$ & $\begin{array}{l}\text { Over- } \\
\text { estimation } \\
(19.2 \pm 0.2 \%)\end{array}$ & & \\
\hline $\begin{array}{l}\text { 10-y ASCVD risk } \\
(\%)\end{array}$ & $8.7 \pm 0.1$ & $12.4 \pm 0.1$ & $8.5 \pm 0.1^{\dagger}$ & $5.7 \pm 0.1^{\dagger}$ & 840.7 & $<0.001$ \\
\hline Age (y) & $55.8 \pm 0.1$ & $59.0 \pm 0.1$ & $55.5 \pm 0.1^{\dagger}$ & $53.4 \pm 0.1^{\dagger}$ & 584.2 & $<0.001$ \\
\hline Women & $52.2 \pm 0.2$ & $36.8 \pm 0.5$ & $50.8 \pm 0.3$ & $72.6 \pm 0.5$ & 777.8 & $<0.001$ \\
\hline $\begin{array}{l}\geq \text { Graduated high } \\
\text { school }\end{array}$ & $67.1 \pm 0.3$ & $57.3 \pm 0.6$ & $68.7 \pm 0.3$ & $72.3 \pm 0.3$ & 178.9 & $<0.001$ \\
\hline $\begin{array}{l}\text { Income } \geq 3 \text { rd } \\
\text { quartile }\end{array}$ & $52.2 \pm 0.3$ & $47.9 \pm 0.5$ & $53.4 \pm 0.4$ & $53.0 \pm 0.5$ & 28.9 & $<0.001$ \\
\hline Current smoker & $18.7 \pm 0.2$ & $25.8 \pm 0.5$ & $18.3 \pm 0.3$ & $12.4 \pm 0.4$ & 176.5 & $<0.001$ \\
\hline $\begin{array}{l}\text { Alcohol drink } \geq \\
\text { once/m }\end{array}$ & $54.1 \pm 0.2$ & $54.9 \pm 0.5$ & $55.5 \pm 0.3$ & $49.1 \pm 0.5$ & 37.1 & $<0.001$ \\
\hline $\begin{array}{l}\text { Regular physical } \\
\text { activity }\end{array}$ & $45.4 \pm 0.2$ & $40.8 \pm 0.5$ & $46.6 \pm 0.3$ & $46.6 \pm 0.5$ & 32.6 & $<0.001$ \\
\hline $\begin{array}{l}\text { Resistance } \\
\text { exercise } \geq \text { once/w }\end{array}$ & $24.0 \pm 0.2$ & $24.7 \pm 0.5$ & $25.2 \pm 0.2$ & $19.1 \pm 0.4$ & 46.4 & $<0.001$ \\
\hline $\begin{array}{l}\text { BMI categories } \\
\left(\mathrm{kg} / \mathrm{m}^{2}\right)\end{array}$ & & & & & 1020.6 & $<0.001$ \\
\hline$<18.5$ & $2.4 \pm 0.1$ & & $3.5 \pm 0.1$ & $1.6 \pm 0.1$ & & \\
\hline $18.5 \sim<25.0$ & $61.9 \pm 0.2$ & $61.1 \pm 0.5$ & $58.0 \pm 0.3$ & $74.9 \pm 0.4$ & & \\
\hline $25.0 \sim 29.9$ & $31.4 \pm 0.2$ & $30.9 \pm 0.5$ & $34.1 \pm 0.3$ & $23.5 \pm 0.4$ & & \\
\hline$\geq 30$ & $4.3 \pm 0.1$ & $8.1 \pm 0.3$ & $4.4 \pm 0.1$ & & & \\
\hline $\begin{array}{l}\text { Perceived body } \\
\text { shape }\end{array}$ & & & & & 1029.8 & $<0.001$ \\
\hline Thin & $14.7 \pm 0.1$ & $63.0 \pm 0.5$ & $3.5 \pm 0.1$ & & & \\
\hline Just right & $41.5 \pm 0.2$ & $29.8 \pm 0.4$ & $58.0 \pm 0.3$ & $1.5 \pm 0.1$ & & \\
\hline Somewhat fat & $35.9 \pm 0.2$ & $7.2 \pm 0.3$ & $34.1 \pm 0.3$ & $71.6 \pm 0.5$ & & \\
\hline Very fat & $7.8 \pm 0.1$ & & $4.4 \pm 0.1$ & $26.9 \pm 0.5$ & & \\
\hline Concurrent & $35.0 \pm 0.2$ & $\begin{array}{r}36.5 \pm 0.5 \\
\text { Page }\end{array}$ & $\begin{array}{l}34.3 \pm 0.3 \\
6 / 20\end{array}$ & $35.8 \pm 0.5$ & 5.9 & $<0.001$ \\
\hline
\end{tabular}


diseases

Depressive mood $\quad 4.6 \pm 0.0 \quad 5.5 \pm 0.1 \quad 4.1 \pm 0.0 \quad 5.1 \pm 0.1 \quad 11.7 \quad<0.001$

ASCVD, atherosclerotic cardiovascular disease; CVD, cardiovascular disease; m, month; w, week; BMI, body mass index.

Values represent weighted $\% \pm$ standard error or estimated marginal mean \pm standard error.

*P-values using cross-tabulation analysis or general linear model of complex sampling design.

${ }^{\dagger} \mathrm{P}<0.001$ compared with individuals who underestimated their weight using a simple contrast test. 
Table 2. Gender-specific association between weight misperception and 10-year ASCVD risk in Korean adults aged 40-79 years without a CVD history

Model $1 \quad$ Model $2 \quad$ Model 3

Men

Weight misperception

10-year ASCVD risk (\%)

$\begin{array}{llll}\text { Under } & 11.5 \pm 0.1^{\dagger} & 11.8 \pm 0.1 & 11.9 \pm 0.1 \\ \text { Accurate } & 11.8 \pm 0.1 & 11.7 \pm 0.1 & 11.7 \pm 0.1 \\ \text { Over } & 11.6 \pm 0.1^{\dagger} & 11.4 \pm 0.1 & 11.2 \pm 0.2^{\dagger}\end{array}$

Weight misperception

10-year ASCVD risk $\geq 7.5 \%$

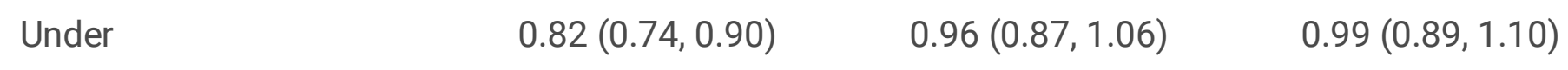

$\begin{array}{llll}\text { Accurate } & 1.00 & 1.00 & 1.00 \\ \text { Over } & 0.87(0.75,1.02) & 0.85(0.73,0.99) & 0.79(0.68,0.92)\end{array}$

Women

Weight misperception

10-year ASCVD risk (\%)

$\begin{array}{llll}\text { Under } & 7.4 \pm 0.1^{\dagger} & 7.5 \pm 0.1^{\dagger} & 7.5 \pm 0.1^{\dagger} \\ \text { Accurate } & 5.5 \pm 0.1 & 5.5 \pm 0.1 & 5.5 \pm 0.1 \\ \text { Over } & 5.5 \pm 0.1 & 5.4 \pm 0.1 & 5.3 \pm 0.1^{\dagger}\end{array}$

Weight misperception

10-year ASCVD risk $\geq 7.5 \%$

Under

$1.29(1.14,1.45)$

$1.44(1.27,1.63)$

$1.42(1.26,1.61)$

Accurate

1.00

1.00

1.00

Over

$1.06(0.94,1.20)$

$1.01(0.90,1.14)$

$0.99(0.87,1.12)$

ASCVD, atherosclerotic cardiovascular disease; CVD, cardiovascular disease; BMI, body mass index.

Values represent estimated marginal mean \pm standard error using complex sample general linear model or odds ratio ( $95 \%$ confidence interval) using complex sample logistic regression after adjusting for age, education, income, alcohol drink, physical activity, resistance exercises, depressive mood, and concurrent diseases (Model 1); the same covariates of model 1 and BMI (Model 2); the same covariates of model 1 and waist circumference (Model 3).

${ }^{\dagger} \mathrm{P}<0.05$ compared with accurate weight estimation using a simple contrast test. 
Table 3. Weight misperception as a moderator in the associations between anthropometrics and the 10-year ASCVD risk among Korean adults aged 40-79 years without a CVD history

Men Women

Association between $\mathrm{BMI}$ and ASCVD risk

$\mathrm{BMI}$

$0.36(0.28,0.43)$

$0.07(0.02,0.12)$

Weight overestimation (vs. accurate estimation)

$-3.57(-9.27,2.12)$

$3.47(0.28,6.66)$

Weight underestimation (vs. accurate estimation)

$-1.08(-3.97,1.81)$

$-5.83(-8.22,-3.44)$

BMl×weight overestimation (vs. accurate estimation)

$0.14(-0.09,0.37)$

$-0.15(-0.28,-0.02)$

BMl×weight underestimation (vs. accurate estimation)

$0.04(-0.09,0.16)$

$0.33(0.23,0.43)$

Association between WC and ASCVD risk

WC

$0.14(0.11,0.17)$

$0.05(0.03,0.07)$

Weight overestimation (vs. accurate estimation) $-3.59(-10.40,3.22)$

$5.68(2.24,9.11)$

Weight underestimation (vs. accurate estimation)

$-3.47(-7.19,0.26)$

$-11.14(-14.17,-8.11)$

WC $\times$ Weight overestimation (vs. accurate estimation)

$0.34(-0.04,0.11)$

$-0.07(-0.11,-0.03)$

WC $\times$ Weight underestimation (vs. accurate estimation)

$0.04(-0.01,0,09)$

$0.16(0.13,0.20)$

ASCVD, atherosclerotic cardiovascular disease; CVD, cardiovascular disease; BMI, body mass index; WC, waist circumference.

Values are regression coefficients $(95 \% \mathrm{Cl})$ on the 10-year ASCVD risk after adjusting for age, education, income, alcohol drink, physical activity, resistance exercises, depressive mood, and concurrent diseases using the PROCESS procedure.

\section{Figures}



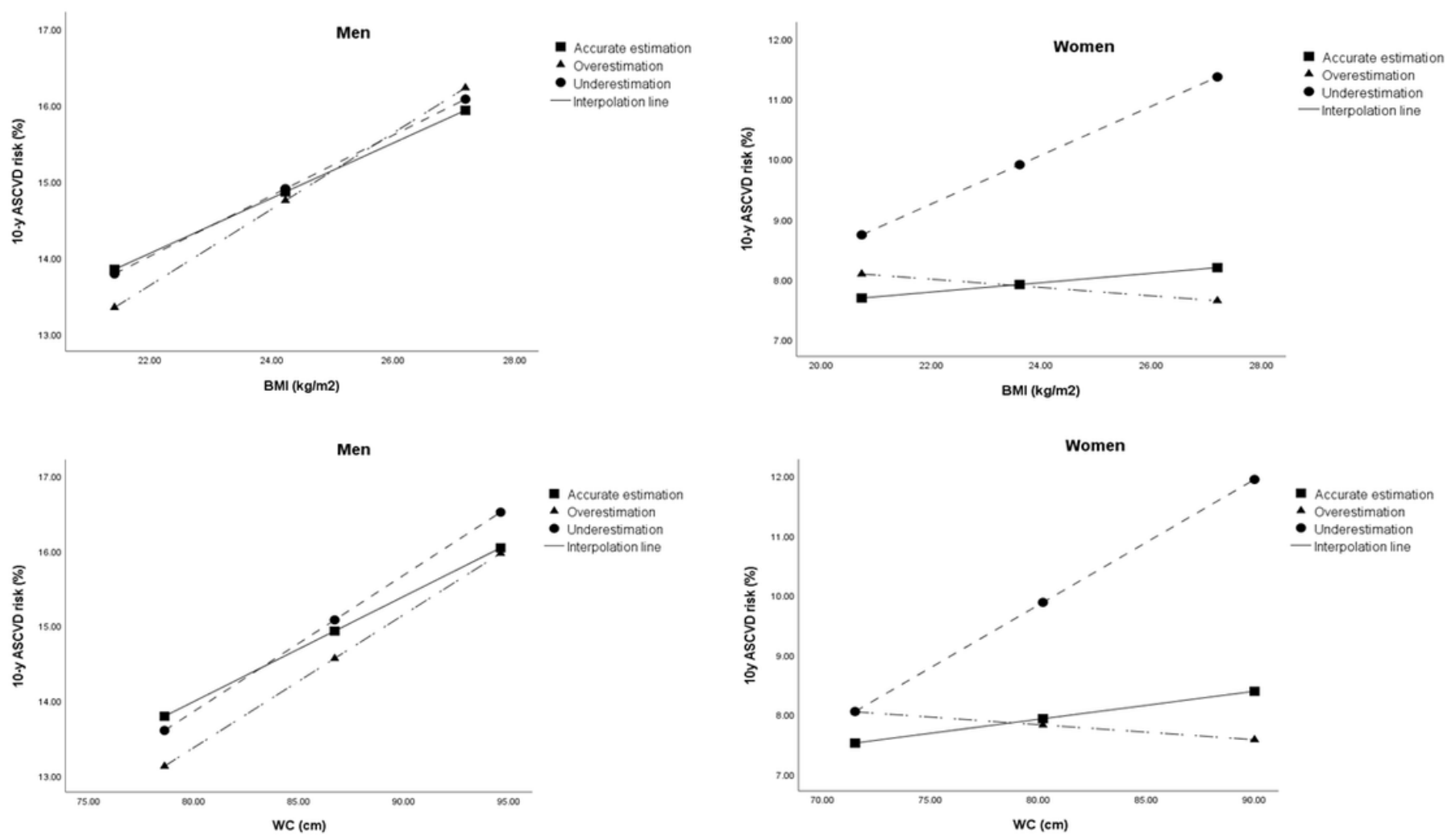

\section{Figure 1}

The moderation of weight misperception on the associations between obesity indices and the 10-year ASCVD risk according to gender ASCVD, atherosclerotic cardiovascular disease; BMI, body mass index; WC, waist circumference. 